University of Nebraska - Lincoln

DigitalCommons@University of Nebraska - Lincoln

Faculty Publications: Department of

Entomology

Entomology, Department of

October 2004

\title{
Monitoring Western Corn Rootworm (Coleoptera: Chrysomelidae) Susceptibility to Carbaryl and Cucurbitacin Baits in the Areawide Management Pilot Program
}

\author{
Blair Siegfried \\ University of Nebraska-Lincoln, bsiegfried1@ufl.edu \\ Lance J. Meinke \\ University of Nebraska-Lincoln, Imeinke1@unl.edu \\ Srivinas Parimi \\ University of Nebraska-Lincoln \\ Michael E. Scharf \\ University of Nebraska-Lincoln \\ Timothy J. Nowatzki \\ University of Nebraska-Lincoln \\ See next page for additional authors \\ Follow this and additional works at: https://digitalcommons.unl.edu/entomologyfacpub \\ Part of the Entomology Commons
}

Siegfried, Blair; Meinke, Lance J.; Parimi, Srivinas; Scharf, Michael E.; Nowatzki, Timothy J.; Zhou, X.; and Chandler, Laurence D., "Monitoring Western Corn Rootworm (Coleoptera: Chrysomelidae) Susceptibility to Carbaryl and Cucurbitacin Baits in the Areawide Management Pilot Program" (2004). Faculty Publications: Department of Entomology. 45.

https://digitalcommons.unl.edu/entomologyfacpub/45

This Article is brought to you for free and open access by the Entomology, Department of at DigitalCommons@University of Nebraska - Lincoln. It has been accepted for inclusion in Faculty Publications: Department of Entomology by an authorized administrator of DigitalCommons@University of Nebraska - Lincoln. 


\section{Authors}

Blair Siegfried, Lance J. Meinke, Srivinas Parimi, Michael E. Scharf, Timothy J. Nowatzki, X. Zhou, and Laurence D. Chandler 


\section{Monitoring Western Corn Rootworm (Coleoptera: \\ Chrysomelidae) Susceptibility to Carbaryl and \\ Cucurbitacin Baits in the Area-wide Management Pilot Program}

Blair D. Siegfried, Lance J. Meinke, Srinivas Parimi, Michael E.

Scharf, Timothy J. Nowatzki, X. Zhou, and Laurence D. Chandler

Journal of Economic Entomology

Volume 97, Issue 5 (October 2004) pp. 1726-1733

DOI: 10.1603/0022-0493(2004)097[1726:MWCRCC]2.0.CO;2

Authors may post electronic reprints of their own journal articles after an embargo period of two years has passed from the date of publication. Also, authors must include on the electronic reprint the following statement:

This article is the copyright property of the Entomological Society of America and may not be used for any commercial or other private purpose without specific written permission of the Entomological Society of America. 


\title{
Monitoring Western Corn Rootworm (Coleoptera: Chrysomelidae) Susceptibility to Carbaryl and Cucurbitacin Baits in the Areawide Management Pilot Program
}

\author{
BLAIR D. SIEGFRIED, LANCE J. MEINKE, SRINIVAS PARIMI ${ }^{1}$ MICHAEL E. SCHARF, ${ }^{2}$ \\ TIMOTHY J. NOWATZKI ${ }^{3} \mathrm{X}$. ZHOU, ${ }^{2}$ AND LAURENCE D. CHANDLER ${ }^{4}$ \\ Department of Entomology, University of Nebraska-Lincoln, Lincoln, NE 68583
}

\begin{abstract}
J. Econ. Entomol. 97(5): 1726-1733 (2004)
ABSTRACT Areawide pest management involves the uniform application of a pest control strategy over wide geographic areas. Therefore, these programs are likely to impose intense selective pressures, and the risk for resistance development among pest species for which areawide management programs are implemented is likely to be high. Pilot studies for areawide management of western corn rootworm, Diabrotica virgifera virgifera LeConte, were conducted from 1996 to 2002 at four different sites across the Corn Belt. This program used cucurbitacin baits to deliver high doses of a traditional neurotoxic insecticide (carbaryl) to individual insects while reducing the overall rate of insecticide use. Because of the concern and potential for resistance evolution, annual assessments of susceptibility to the active ingredient carbaryl were conducted both within the managed area as well as from untreated control areas. Significantly reduced susceptibility to carbaryl based on survival at a diagnostic concentration was detected in three of the four management sites (Kansas, Iowa, and Illinois/Indiana), whereas susceptibility of beetles collected outside the managed areas remained unchanged. Additionally, significantly reduced responsiveness to cucurbitacin baits was observed in beetles collected from the managed area relative to the control area at the same three sites. These results suggest strongly that areawide management has the potential to select for resistance and that a strategy for managing resistance and reducing selective pressure should be proactively implemented.
\end{abstract}

KEY WORDS insecticide resistance, areawide management, esterase, carbaryl, cucurbitacins

THE AREAWIDE MANAGEMENT CONCEPT was developed by various groups in the 1970s and 1980s (Pruess et al. 1974, Rummel 1976, Bottrell and Rummel 1978, Rabb 1978, Huber et al. 1979, Knipling 1980, Kunz et al. 1983) to control key pests (i.e., perennially occurring species that in the absence of control tactics remain at population levels above economic injury levels (Smith and van den Bosch 1967). These key pests regularly cause economic loss, and control programs in a given commodity have historically relied on ecologically disruptive pesticides applied on an annual basis. The objective of areawide management is to systematically reduce a target pest below a low residual level through the use of uniformly applied control measures over large defined geographic areas. The intent is not to eradicate the pest but to achieve and maintain an overall reduced general equilibrium density of the pest population over a large area.

\footnotetext{
${ }^{1}$ Maharashtra Hybrid Seeds Company Ltd., Jalna-Auranagabad Rd., P.O. Box 76, Jalna 431 203, Maharashtra, India.

${ }^{2}$ Department of Entomology and Nematology, University of Florida, Gainesville, FL 32611.

${ }^{3}$ Pioneer Hi-Bred International, P.O. Box 1004, Johnston, IA 50131

${ }^{4}$ Red River Valley Agricultural Research Center, USDA-ARS, Fargo, ND 58105-5677.
}

Pilot studies for areawide management of the western corn rootworm, Diabrotica virgifera virgifera LeConte, were conducted from 1996 to 2002 at four different sites across the Corn Belt. The primary management tool in these programs exploited behavioral adaptations of Diabrotica spp. to feeding stimulants and arrestants to deliver high doses of a traditional neurotoxic insecticide to individual insects (Comis 1997) while minimizing the overall rate of insecticide use. The management tool chosen for rootworm areawide programs consisted of a semiochemical bait formulation (SLAM) containing a combination of adult movement arrestants and feeding stimulants (multiple forms of cucurbitacin) and the acetyl cholinesteraseinhibiting toxicant carbaryl (Comis 1997).

The goal of resistance risk assessment is to predict the potential rate and extent of resistance development in response to use of a pesticide in a particular environment (Tabashnik 1992). Specifically, resistance risk assessment is the process of estimating the relative influence of different factors on increasing resistance genotype frequencies in pest populations exposed to selective agents. Given the potential for intense selection by using an areawide management approach, the risk of resistance development for a 
given areawide management program would be expected to be high (Siegfried et al. 1998). This risk is magnified for western corn rootworms when its previous history of resistance development is factored into the assessment. Many examples exist of western corn rootworm adaptation to uniform, large-scale agricultural practices. Resistance to soil-applied organochlorine insecticides first became apparent in the late 1950s and early 1960s (Ball and Weekman 1963). As a result, producers in south central Nebraska began a practice of aerial applications of insecticides to suppress beetle populations and subsequently manage larval damage the following season (Meinke 1995). Various studies demonstrated that adult corn rootworm populations could be greatly reduced by aerial applications of insecticides (Hill et al. 1948, Pruess et al. 1974, Mayo 1976). These studies documented that control of adult rootworms during ovipositional periods could be used to prevent economic loss from larval feeding the following season. Extensive use of carbamate and organophosphate insecticides in Nebraska during the 1970s to early 1990s provided good adult and larval corn rootworm control. However, reports of insecticide control failures had become common by 1995, and resistance documentation for methyl-parathion was confirmed by Meinke et al. (1998) and Miota et al. (1998).

Given the history of resistance development by western corn rootworms and the potential for areawide management to impose intense selective pressures over large geographic areas, we initiated a monitoring program to determine whether changes in susceptibility had occurred during consecutive years that the areawide program was practiced. Annual assessments of susceptibility to the active ingredient of the cucurbitacin bait formulation (carbaryl) were conducted both within management areas as well as from control areas outside the program. Susceptibility was determined both with traditional concentrationresponse assays as well as diagnostic concentration assays validated with populations known to be resistant to carbaryl (Scharf et al. 1999a). Biochemical assays (Zhou et al. 2002) also were conducted to determine potential changes in activity of specific detoxification enzymes known to at least partially contribute to carbaryl resistance (Scharf et al. 1999b). Finally, at the end of the program, feeding behavior assays with cucurbitacin baits (Parimi et al. 2003) were conducted to determine whether responsiveness to cucurbitacin baits had changed after exposure to the bait formulation for consecutive years of the program.

\section{Materials and Methods}

Areawide Sites/Rootworm Collections. Areawide management sites were located in Brookings County, South Dakota; Republic County, Kansas; Clinton County, Iowa; and on the Illinois-Indiana border, including both Iroquois County, Illinois, and Newton County, Indiana. Each site provided a different agronomic/climatic environment. An annual corn-soybean rotation was practiced on a high percentage of hectares in the Illinois-Indiana site, whereas a higher percentage of continuous corn production was common to the other sites. Corn was irrigated at the Kansas site, whereas crops were rain-fed at the other sites. The Illinois-Indiana site was located where the western corn rootworm had adapted to crop rotation (i.e., western corn rootworm variant, Levine et al. 2002) and adults were laying a significant number of eggs in both corn and soybean, resulting in annual adult production from first year and continuous corn. Rotation from corn to soybean was still an effective management technique at the other areawide sites, so western corn rootworms only developed in fields planted in corn the previous year.

Each site included a $41.4-\mathrm{km}^{2}\left(16-\mathrm{mi}^{2}\right)$ managed area that consisted of a mosaic of corn and soybean fields. In South Dakota, Kansas, and Iowa, semiochemical-based baits were annually applied to each cornfield for adult western corn rootworm control if adult densities exceeded the established threshold. In the Illinois-Indiana site, baits were applied to individual corn and soybean fields if adult thresholds were exceeded during 1997-1999, but in 2000-2001 the managed area was divided into large blocks (multiple fields) that were treated if one soybean field in the block exceeded threshold. Semiochemical-based baits used during the pilot program were SLAM (buffalo gourd, Cucurbita foetidissima H.B.K., root powder, $87 \%$, with $13 \%$ carbaryl encapsulated in a microsphere, MicroFlo Inc., Memphis, TN) or (later in the program) two adjuvant-based products, CideTrak (Trécé Inc., Salinas, CA), and Invite EC (Florida Food Products Agrochemicals, Eustis, FL), each tank mixed with low rates of carbaryl. At each management site, specific cornfields located adjacent or in proximity to the managed area were designated as control fields. Control fields were representative of the agronomic and rootworm management practices of the region surrounding the managed areas and were not subjected to adult management. The number and size of fields designated as control fields varied by site.

From 1997 to 2002 , collections of western corn rootworm adults were annually made by cooperators at each site from multiple fields in both the managed and control areas. Collections were made from corn at all sites. Additional collections also were made from soybean at the Illinois-Indiana site. Managed area collections were made before baits were applied. Beetles were pooled within managed or control areas and then shipped overnight to the University of Nebraska-Lincoln. Beetles also were annually collected from a specific continuous cornfield in Saunders County, Nebraska, and York County, Nebraska, for use as standard carbaryl-susceptible and -resistant populations, respectively. All beetles were provided with corn ears or soybean leaves as food during transport to maintain diet consistency with the crop they were collected from. Beetles were maintained in plastic cages on the appropriate corn or soybean diet at $22-25^{\circ} \mathrm{C}$ in the laboratory for $24-48 \mathrm{~h}$ before use in bioassays.

Chemicals. Technical grade carbaryl (99.5\% [AI]) was purchased from Chem Services Inc. (West Ches- 
ter, PA). All insecticide dilutions were prepared in reagent grade acetone $(>99.5 \%$ purity; EM Scientific, Gibbstown, NJ). Invite EC (80\% principal functioning agent) was obtained from Florida Food Products Agrochemicals.

Bioassays. Carbaryl bioassays were conducted with technical grade carbaryl by using a diagnostic concentration $(5.0 \mu \mathrm{g} / \mathrm{ml})$ in $20-\mathrm{ml}$ glass scintillation vials that corresponded to the $\mathrm{LC}_{99}$ of a standard susceptible population (Scharf et al. 1999a). Vials were treated with $500 \mu \mathrm{l}$ of insecticide solution (in acetone) and were dried by rolling in a fume hood. Ten unsexed beetles were placed in each vial and held at $22^{\circ} \mathrm{C}$ in darkness for $24 \mathrm{~h}$ after which mortality was recorded as a lack of coordinated movement. Each test population consisted of 10 carbaryl-treated and two acetone-treated vials. Bioassays also were conducted using a range of carbaryl concentrations (0.625-20 $\mu \mathrm{g} /$ $\mathrm{ml})$ that produced between 0 and $100 \%$ mortality and were replicated over $2 \mathrm{~d}$.

Native Polyacrylamide Gel Electrophoresis (PAGE). Native (nondenaturing) PAGE was conducted on $8 \%$ resolving gels with $4 \%$ stacking gels and a discontinuous Tris-glycine running buffer system. Rootworm abdomens were placed into individual wells of a 96-well flat bottom microplate (353912 FALCON, BD Biosciences, Franklin Lakes, NJ) containing $100 \mu \mathrm{l}$ of ice-cold $0.2 \mathrm{M}$ sodium phosphate homogenization buffer ( $\mathrm{pH} 7.8,0.1 \%$ Triton X-100). Abdomens were homogenized by a combination of vertical and circular movements of a 96-spoke inoculating manifold (MC96, Dan-Kar, Reading, MA) for 30 s. Six microliters of abdominal homogenates was mixed with $1.5 \mu \mathrm{l}$ of loading buffer (Tris-glycine running buffer containing $20 \%$ sucrose and $0.05 \%$ xylene cyanol) before loading onto the gels. Electrophoresis was conducted at $4^{\circ} \mathrm{C}$ and $120 \mathrm{~V}$ for $2.5-3 \mathrm{~h}$, after which gels were placed in $0.02 \mathrm{M}$ sodium phosphate buffer (pH 7.0) containing $20 \mathrm{mM} \beta$-naphthyl acetate in acetone. After 5 min, esterase bands were visualized by the addition of $1 \mathrm{ml}$ of water containing $20 \mathrm{mg}$ of fast blue $\mathrm{BN}$ (tetrazotized $\mathrm{O}$-dianisidine). The gels were destained in gel drying solution, scored for the presence of elevated "group II" esterase bands (Zhou et al. 2002) and dried for storage. At least 30 individuals were analyzed for each population.

Feeding Behavior Assays. During the last year of the areawide program, no-choice feeding assays were conducted with adult rootworms from the managed and control areas of each areawide site to evaluate responsiveness to a cucurbitacin-based bait. A 10-fold dilution of the Invite formulation was dispensed onto a regenerated cellulose membrane disk $(0.45-\mu \mathrm{m}$ pore size, 13- $\mathrm{mm}^{2}$ diameter, Schleicher \& Schuell, Keene, NH) in a 20- $\mu$ l droplet (Hollister and Mullin 1999, Parimi et al. 2003). Air-dried disks were positioned on minuten pins above moistened Whatman No. 2 filter paper in petri dishes containing a paraffin bottom. Each treatment was replicated 10 times with four beetles (two each of male and female) placed in each petri dish and held at $22^{\circ} \mathrm{C}$ in total darkness. The consumed disk areas were measured after $6 \mathrm{~h}$ of feed- ing to the nearest $0.01 \mathrm{~cm}^{2}$ by using a LICOR-3000 area meter (LICOR, Lincoln, NE). Ten disks were used to calculate the mean disk area before feeding. Percentage of disk consumption was calculated by subtracting the area consumed from the mean disk area.

Statistical Analysis. Lethal concentration data were analyzed by probit analysis (Finney 1971) by using POLO-PC (LeOra Software 1987). Changes in percentage of mortalities derived from diagnostic bioassays were regressed against time over the $6 \mathrm{yr}$ that bioassays were conducted. Feeding bioassay data were analyzed with PROC GLM, which compared differences in percentage disk consumption by beetles between treatments. Significance of differences among treatment means were determined using the least significant difference (LSD) test at $\alpha=0.05$ (SAS Institute 2001).

\section{Results}

Insecticide Bioassays. Results of bioassays (19972002 ) to estimate susceptibility of the various area wide collections to carbaryl are presented in Table 1. The resistant population (Nebraska-R) used in this study demonstrated consistently higher $\mathrm{LC}_{50}$ values for carbaryl compared with the susceptible (Nebraska-S) (resistance ratio varied from 2.1 to 5.7) (Table 1). The $\mathrm{LC}_{50}$ values of collections from Indiana/ Illinois-managed (Soybean), SD managed, and all the untreated control areas remained consistent compared with the susceptible population throughout the study. However, reduced beetle susceptibility was observed over time in the other managed areas during the same period. Specifically, the $\mathrm{LC}_{50}$ of beetle collections from managed areas in Iowa, Kansas, and Indiana/Illinois corn increased 1.5- tol.8-fold from 1997 to 2002 (Table 1). Although these changes are subtle, they do suggest a pattern of reduced susceptibility associated with repeated exposure to carbaryl.

Diagnostic Bioassays. Percentage of mortality at the diagnostic carbaryl concentration of the collections from Indiana/Illinois soybean, and Nebraska $-\mathrm{S}$ and -R populations did not change during the 6-yr study (Fig. 1D and F). The diagnostic mortalities of collections from control areas in Iowa, Kansas, and Indiana/ Illinois corn exhibited slight changes during the same period, but the slopes of the regression curves were not significantly different from zero (Fig. 1A-C). In contrast, percentage of mortality at the diagnostic concentration of the collections from managed areas in Iowa, Kansas, and Indiana/Illinois corn all exhibited significant changes in susceptibility (Fig. 1A-C). A continuous and consistent decrease in susceptibility of managed area collections from Kansas (91.7-78.4\%), Iowa (100-82\%), and Indiana/Illinois corn (100-83.3\%) occurred between 1997 and 2002 based on diagnostic bioassays with carbaryl.

Native PAGE. Intense resistance-associated "group II" esterase bands were consistently observed in the Nebraska-R population throughout the study (Fig. 2). Elevated resistance-associated esterase activity was not observed in individuals from any areawide man- 
Table 1. Results of probit analysis of carbaryl toxicity as assessed by exposure to carbaryl residues after $24 \mathrm{~h}$ for collections of $\mathrm{D}$. virgifera virgifera adults from different areawide management sites

\begin{tabular}{|c|c|c|c|c|c|}
\hline Collection $^{a}$ & $n^{b}$ & $\chi^{2^{c}}$ & Slope $( \pm \mathrm{SE})$ & $\begin{array}{c}\mathrm{LC}_{50} \\
(95 \% \mathrm{CI})^{d}\end{array}$ & $\begin{array}{c}\mathrm{LC}_{90} \\
(95 \% \mathrm{CI})^{d}\end{array}$ \\
\hline \multicolumn{6}{|l|}{1997} \\
\hline Nebraska-S & 150 & 0.9 & $4.1(0.8)$ & $1.7(1.30-2.02)$ & $3.40(2.72-5.13)$ \\
\hline Nebraska-R & 150 & 0.4 & $2.4(0.4)$ & $7.5(5.83-9.84)$ & $26.3(17.8-54.8)$ \\
\hline Iowa $(\mathrm{M})$ & 300 & 0.5 & $5.2(0.6)$ & $1.5(1.40-1.71)$ & $2.7(2.41-3.28)$ \\
\hline Iowa (C) & 360 & $2.2 *$ & $2.5(0.3)$ & $2.1(1.14-3.26)$ & $6.9(4.2-23.23)$ \\
\hline Kansas (M) & 420 & $1.7^{*}$ & $2.3(0.2)$ & $1.8(1.28-2.34)$ & $6.6(4.43-12.90)$ \\
\hline Kansas (C) & 420 & 0.7 & $3.4(0.3)$ & $1.8(1.62-2.08)$ & $4.3(3.62-5.38)$ \\
\hline Ind./ Ill. (CN-M) & 300 & $2.7^{*}$ & $3.4(0.4)$ & $1.2(0.60-1.82)$ & $2.9(1.88-9.04)$ \\
\hline Ind./Ill. (CN-C) & 300 & 1.1 & $3.3(0.4)$ & $1.2(0.70-1.74)$ & $2.9(1.98-7.87)$ \\
\hline Ind./Ill. (SO-M) & 300 & 0.4 & $3.6(0.5)$ & $0.7(0.63-0.82)$ & $1.7(1.37-2.16)$ \\
\hline Ind./Ill. (SO-C) & 240 & $2.1^{*}$ & $3.1(0.6)$ & $0.5(0.46-)$ & 1.3 (not calculated) \\
\hline South Dakota (M) & \multicolumn{5}{|c|}{ Analysis not performed } \\
\hline South Dakota (C) & 240 & $2.7^{*}$ & $4.4(0.6)$ & $0.9(0.48-1.43)$ & $1.9(1.33-5.96)$ \\
\hline \multicolumn{6}{|l|}{1998} \\
\hline Nebraska-S & 360 & 1.1 & $2.8(0.3)$ & $1.37(1.16-1.59)$ & $3.93(3.22-5.14)$ \\
\hline Nebraska-R & 360 & 3.2 & $1.7(0.1)$ & $2.83(2.19-3.51)$ & $15.9(11.90-23.79)$ \\
\hline Iowa $(\mathrm{M})$ & 100 & 1.0 & $3.0(0.6)$ & $1.39(0.97-1.84)$ & $3.69(2.68-6.53)$ \\
\hline Iowa $(\mathrm{C})$ & 100 & 1.8 & $2.9(0.9)$ & $1.33(0.58-1.94)$ & $3.64(2.47-9.43)$ \\
\hline Kansas (M) & 240 & $16.8^{*}$ & $2.7(0.3)$ & $1.79(0.79-3.26)$ & $5.31(2.98-30.83)$ \\
\hline Kansas (C) & 200 & 0.4 & $3.6(0.4)$ & $1.67(1.41-1.96)$ & $3.81(3.10-5.13)$ \\
\hline Ind./Ill. (CN-M) & 200 & 2.7 & $3.0(0.4)$ & $1.00(0.43-1.57)$ & $2.67(1.68-16.02)$ \\
\hline Ind./Ill. (CN-C) & 160 & $3.0^{*}$ & $2.7(0.4)$ & $1.07(0.61-1.54)$ & $3.24(2.10-10.47)$ \\
\hline Ind./IIl. (SO-M) & 90 & $3.1^{*}$ & $4.3(0.8)$ & $0.75(0.38-1.03)$ & $2.36(1.62-6.42)$ \\
\hline Ind./Ill. (SO-C) & 150 & 0.2 & $3.3(1.1)$ & $0.35(0.09-0.51)$ & $0.86(0.67-1.25)$ \\
\hline South Dakota (M) & 250 & $7.3^{*}$ & $2.3(0.3)$ & $1.34(0.59-2.19)$ & $4.89(2.82-25.0)$ \\
\hline South Dakota (C) & 200 & 1.1 & $3.4(0.4)$ & $1.10(0.93-1.28)$ & $2.66(2.18-3.59)$ \\
\hline \multicolumn{6}{|l|}{1999} \\
\hline Nebraska-S & 200 & 0.3 & $4.4(1.2)$ & $1.31(0.92-1.85)$ & $3.06(2.14-5.33)$ \\
\hline Nebraska-R & 240 & 0.5 & $3.1(0.7)$ & $7.52(5.42-10.4)$ & $17.54(12.35-30.9)$ \\
\hline Iowa $(\mathrm{M})$ & 300 & 3.0 & $3.4(0.4)$ & $1.42(1.23-1.64)$ & $3.38(2.85-4.17)$ \\
\hline Iowa (C) & 300 & 0.3 & $3.5(0.4)$ & $1.52(1.32-1.76)$ & $3.61(3.04-4.46)$ \\
\hline Kansas (M) & 350 & $3.6^{*}$ & $3.0(0.3)$ & $1.57(1.12-2.16)$ & $3.62(2.58-6.16)$ \\
\hline Kansas (C) & 250 & $8.0^{*}$ & $5.0(0.4)$ & $1.24(0.88-1.75)$ & $2.87(2.01-4.98)$ \\
\hline Ind./Ill. (CN-M) & 250 & 0.1 & $3.2(0.5)$ & $0.64(0.52-0.77)$ & $1.40(1.15-1.76)$ \\
\hline Ind./Ill. (CN-C) & 250 & $2.2 *$ & $3.2(0.4)$ & $0.58(0.49-0.68)$ & $1.27(1.07-1.57)$ \\
\hline Ind./Ill. (SO-M) & 250 & 0.7 & $4.9(0.7)$ & $0.41(0.34-0.49)$ & $0.90(0.75-1.10)$ \\
\hline Ind./Ill. (SO-C) & 250 & 0.1 & $4.8(0.7)$ & $0.46(0.39-0.55)$ & $1.02(0.84-1.26)$ \\
\hline South Dakota (M) & 250 & $3.5^{*}$ & $5.8(0.7)$ & $1.29(1.00-1.64)$ & $3.12(2.38-4.42)$ \\
\hline South Dakota (C) & 60 & 1.0 & $2.7(0.6)$ & $1.10(0.58-1.57)$ & $2.30(1.40-4.11)$ \\
\hline \multicolumn{6}{|l|}{2000} \\
\hline Nebraska-S & 300 & 2.20 & $4.1(0.48)$ & $1.32(1.15-1.50)$ & $2.68(2.25-3.42)$ \\
\hline Nebraska-R & 240 & 5.21 & $2.6(0.30)$ & $4.52(3.35-6.08)$ & $14.22(9.80-26.0)$ \\
\hline Iowa $(\mathrm{M})$ & $\begin{array}{l}240 \\
296\end{array}$ & $\begin{array}{l}5.21 \\
7.60^{*}\end{array}$ & $2.3(0.25)$ & $2.20(1.50-3.20)$ & $7.96(5.00-20.2)$ \\
\hline Iowa (C) & 300 & $7.75^{*}$ & $2.4(0.25)$ & $2.10(1.40-3.00)$ & $7.24(4.60-17.6)$ \\
\hline Kansas (M) & 353 & 2.56 & $\begin{array}{l}2.4(0.2 .)) \\
2.5(0.25)\end{array}$ & $1.85(1.53-2.40)$ & $6.22(4.90-8.57)$ \\
\hline Kansas (C) & 351 & 3.19 & $3.1(0.36)$ & $1.23(1.00-1.43)$ & $3.18(2.60-4.22)$ \\
\hline Ind./Ill. (CN-M) & 300 & 0.58 & $2.5(0.30)$ & $1.47(1.15-1.81)$ & $4.86(3.78-6.94)$ \\
\hline Ind./Ill. (CN-C) & 300 & $\begin{array}{l}0.00 \\
1.46\end{array}$ & $3.1(0.37)$ & $1.18(0.99-1.38)$ & $3.07(2.50-4.13)$ \\
\hline South Dakota (M) & 294 & $13.7^{*}$ & $2.5(0.28)$ & $1.36(0.86-2.02)$ & $3.83(2.52-7.84)$ \\
\hline South Dakota (C) & 299 & 1.81 & $3.5(0.44)$ & $1.00(0.60-1.53)$ & $2.72(1.84-5.67)$ \\
\hline \multicolumn{6}{|l|}{2001} \\
\hline Nebraska-S & 350 & 1.00 & $2.9(0.28)$ & $1.36(1.16-1.59)$ & $4.46(3.47-5.81)$ \\
\hline Nebraska-R & 320 & 2.82 & $1.8(0.18)$ & $7.37(6.01-9.59)$ & $24.24(18.6-32.0)$ \\
\hline Iowa $(\mathrm{M})$ & 350 & $10.5^{*}$ & $2.9(0.29)$ & $1.72(1.12-2.57)$ & $5.64(4.34-7.35)$ \\
\hline Iowa (C) & 350 & 1.47 & $2.9(0.31)$ & $1.50(1.29-1.80)$ & $4.90(3.80-6.40)$ \\
\hline Kansas (M) & 350 & 2.57 & $1.9(0.20)$ & $1.90(1.40-2.19)$ & $6.26(4.92-8.08)$ \\
\hline Kansas (C) & 350 & 0.95 & $2.3(0.25)$ & $1.47(1.15-1.73)$ & $4.82(3.75-6.27)$ \\
\hline Ind./ Ill. (CN-M) & 300 & $4.13^{*}$ & $1.9(0.24)$ & $1.99(1.18-2.92)$ & $6.53(5.10-8.50)$ \\
\hline Ind./Ill. (CN-C) & 300 & 1.33 & $2.0(0.25)$ & $1.35(0.95-1.56)$ & $4.44(3.45-5.77)$ \\
\hline South Dakota (M) & 300 & 1.97 & $3.4(0.37)$ & $1.36(1.22-1.66)$ & $4.48(3.45-5.88)$ \\
\hline South Dakota (C) & 360 & 1.72 & $2.2(0.28)$ & $0.84(0.57-0.98)$ & $2.77(2.16-3.57)$ \\
\hline \multicolumn{6}{|l|}{2002} \\
\hline Nebraska-S & 280 & 1.46 & $2.8(0.30)$ & $1.43(1.16-1.76)$ & $4.76(3.83-5.98)$ \\
\hline Nebraska-R & 320 & 1.12 & $2.2(0.22)$ & $6.00(4.92-7.35)$ & $19.96(16.1-25.0)$ \\
\hline Iowa (M) & 350 & 2.10 & $2.1(0.21)$ & $2.36(1.96-2.82)$ & $7.82(6.45-9.59)$ \\
\hline Iowa (C) & 280 & 0.59 & $2.6(0.39)$ & $0.88(0.70-1.15)$ & $2.93(2.32-3.74)$ \\
\hline Kansas (M) & 400 & $5.21^{*}$ & $2.0(0.18)$ & $2.73(2.28-3.26)$ & $9.05(7.50-11.1)$ \\
\hline Kansas (C) & 240 & 1.91 & $3.0(0.42)$ & $1.02(0.81-1.28)$ & $3.34(2.67-4.27)$ \\
\hline Ind./Ill. $(\mathrm{CN}-\mathrm{M})$ & 240 & $3.93^{*}$ & $2.6(0.31)$ & $1.82(1.47-2.25)$ & $6.04(4.85-7.62)$ \\
\hline Ind./Ill. (CN-C) & 240 & 0.45 & $2.9(0.37)$ & $1.33(1.07-1.66)$ & $4.42(3.53-5.59)$ \\
\hline South Dakota (M) & 300 & 0.96 & $3.1(0.35)$ & $1.27(1.04-1.55)$ & $4.22(3.43-5.23)$ \\
\hline South Dakota (C) & 300 & 0.15 & $3.0(0.39)$ & $1.00(0.81-1.23)$ & $3.32(2.68-4.14)$ \\
\hline
\end{tabular}

${ }^{a}$ Each collection provided from the four management areas: C, control area, larval control with soil insecticides; M, managed area, adult control with semiochemical baits. Nebraska-S and -R are carbaryl-susceptible and carbaryl-resistant reference populations, respectively, that were collected annually from specific fields in Nebraska. All collections in Nebraska, Iowa, Kansas, and South Dakota from corn; Indiana/ Illinois collections from corn (CN) and soybean (SO) from 1997 to 1999

${ }^{b}$ The total number of insects used in each bioassay.

${ }^{c} \chi^{2}$ goodness-of-fit statistics as determined using POLO-PC software (LeOra Software 1987). Degrees of freedom ranged from 2 to 4 , and numbers followed by an * indicate departures from an expected model based on heterogeneity factors $>1.0$ (i.e., $\chi^{2} / \mathrm{df}>1.0$ ).

${ }^{d}$ Lethal concentrations of carbaryl (micrograms per milliliter) with $95 \% \mathrm{CI}$ at the $50 \%\left(\mathrm{LC}_{50}\right)$ and $90 \%\left(\mathrm{LC}_{90}\right)$ levels of probit mortality. 


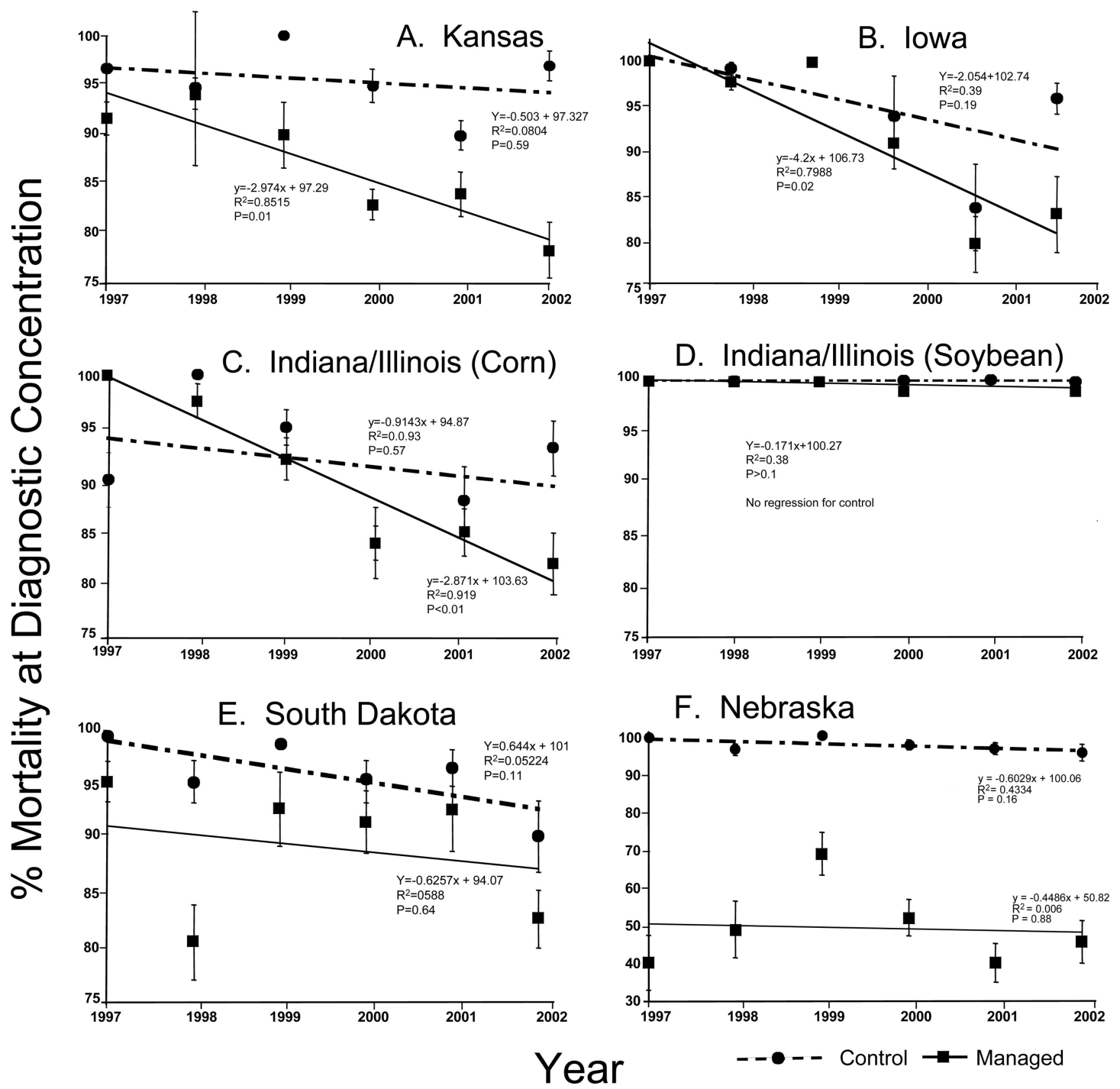

Fig. 1. Mortality of adult western corn rootworms from areawide management programs collected from the control and managed areas at a diagnostic carbaryl concentration. Data collected from $6 \mathrm{yr}$ of the pilot program. A-F correspond to management sites except for the Nebraska (F) figure, which presents data from the reference-susceptible and -resistant populations.

agement sites in 1999, except for the managed area collection from South Dakota (Fig. 2). However, in one or more years during 2000-2002, some individuals exhibited elevated esterase activity in all collection areas except Iowa control, SD managed and control, and Indiana/Illinois soybean managed and control.

Feeding Behavior Assays. The Invite formulation tested in feeding assays significantly stimulated disc consumption by adults from all collection areas tested (Fig. 3). However, the mean consumption of cellulose membrane disks treated with Invite was significantly reduced $(10-20 \%)$ in individuals from the managed areas relative to the control areas in three of the four management sites (Kansas, Iowa, and Illinois/Indiana).

\section{Discussion}

The collective results of this investigation suggest that $D$. v. virgifera has the potential to evolve behavioral and physiological resistance to the insecticidal baits used in areawide management pilot programs. More specifically, these results indicate that significant changes in susceptibility occurred in three of the four areawide management sites, based on reduced mortality of rootworm adults at a diagnostic carbaryl concentration. The results from concentration-response assays (i.e., $\mathrm{LC}_{50}$ and $\mathrm{LC}_{90}$ ) also show a generally reduced susceptibility of rootworm populations exposed to areawide management programs, although the differences were not as large as observed in diag- 


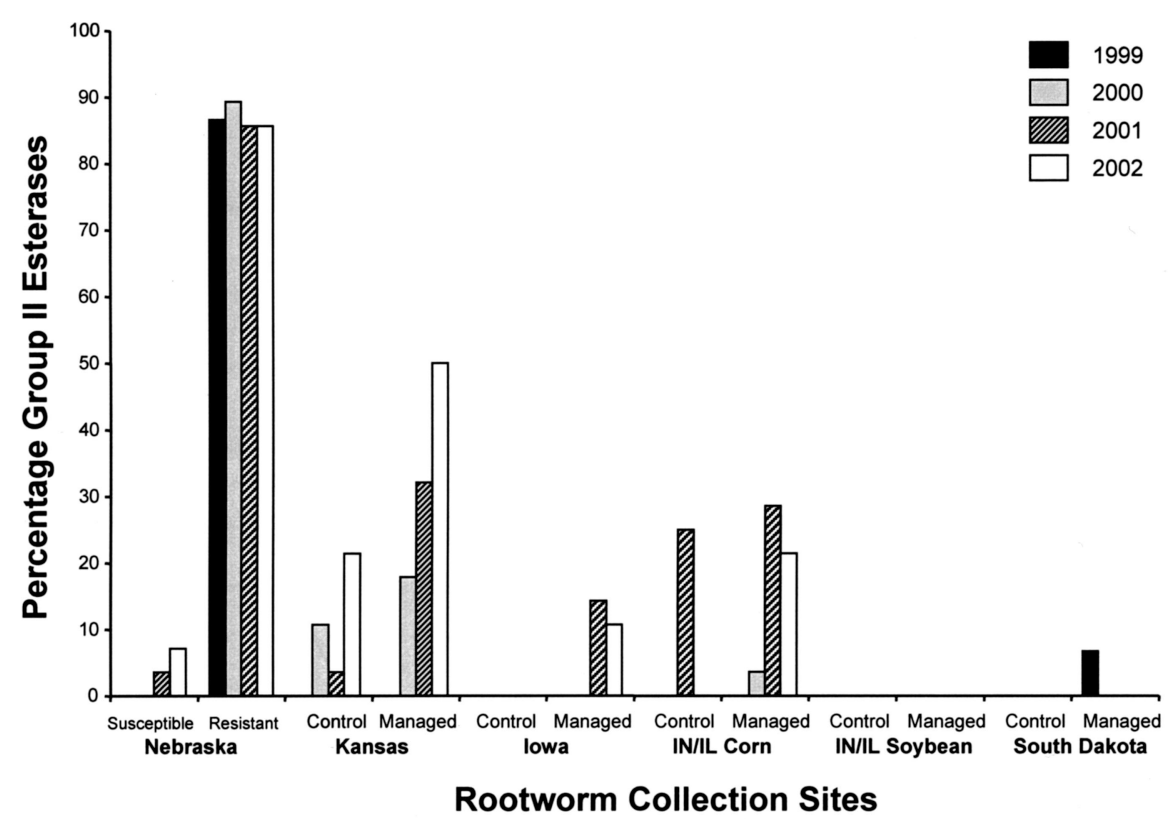

Fig. 2. Percentage of individuals $(n=30)$ exhibiting elevated group II esterases in individual rootworm homogenates from different areawide sites and the carbaryl-susceptible and -resistant populations from Nebraska. See Materials and Methods for details regarding the managed and control areas.

nostic bioassays. Additionally, the percentage of individual beetles exhibiting elevated group II esterases as determined by native PAGE was consistently higher among beetles collected from treated areas, especially during the last $3 \mathrm{yr}$ of the program.

It should be noted that beetles collected from managed areas of the South Dakota site and the Indiana/ Illinois soybean site did not exhibit changes in carbaryl susceptibility. In the case of beetles collected from soybean fields from Indiana/Illinois, rootworm adults that consume soybean foliage are generally less fit than beetles consuming corn tissues ( $\mathrm{O}^{\prime} \mathrm{Neal}$ et al. 2002 ) such that differences in carbaryl susceptibility may have been masked by the effects of soybean foliage consumption. The uniqueness of the South Dakota site may have contributed to the results obtained in this study. A preponderance of the South Dakota fields were rotated annually $(>75 \%$ corn-soybean rotation), increasing densities of extended diapause populations of the northern corn rootworm, Diabrotica barberi Smith \& Lawrence, were present, and the western corn rootworm variant adapted to

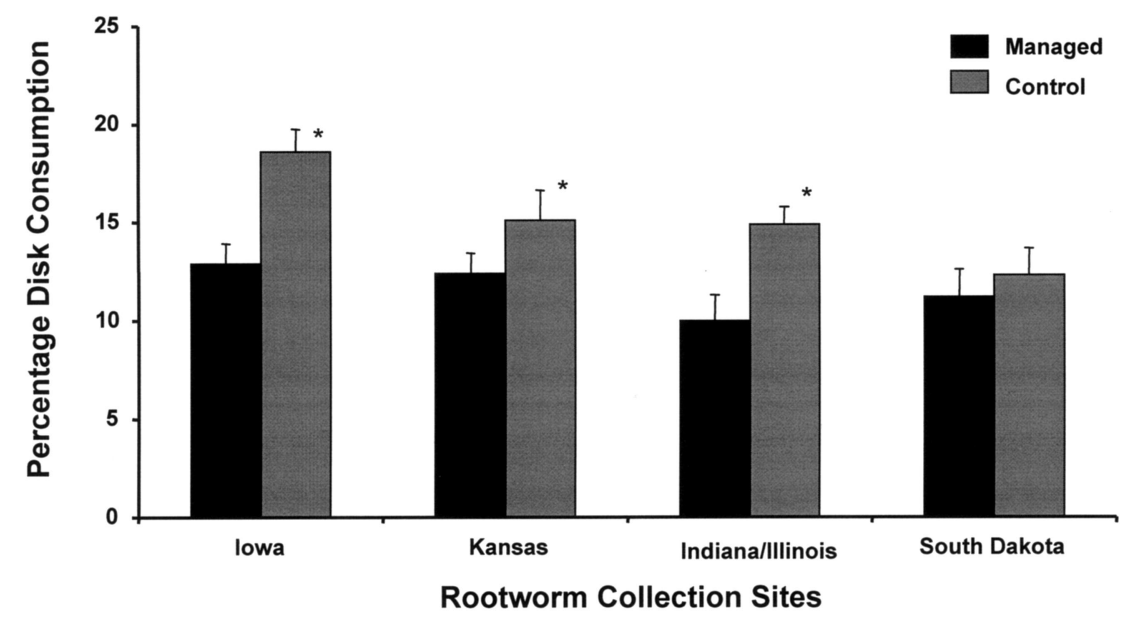

Fig. 3. Percentage of cucurbitacin-treated discs consumed by western corn rootworm adults collected from areawide management sites in the managed and control areas. * indicates significant difference $(P<0.05)$ between managed and control areas. See Materials and Methods for details regarding the managed and control areas. 
corn rotation was absent (L.D.C., unpublished data). Another key factor was that the overall density of western corn rootworms dramatically declined at the site during the 6-yr study (L.D.C., unpublished data). The number of bait applications annually applied was fairly consistent during the 6-yr study and therefore general selection intensity was apparently consistent throughout. Moreover, cucurbitacin-based carbaryl baits had been used at this site for a number of years before use at the other three sites. However, because the annual number of continuous cornfields at the site was low (primary producer of western corn rootworm) and the proportion that received bait applications also was relatively low (average 41\% 1997-2000; L.D.C., unpublished data), the majority of bait applications was made to first year cornfields to manage the northern corn rootworm. Therefore, data suggest that a complex interaction of crop rotation and annual bait applications to only a subset of continuous cornfields may have effectively reduced western corn rootworm density without significantly changing the carbaryl susceptibility level of the western corn rootworm population.

In contrast to the changes in adult susceptibility observed within the managed areas of three sites, no significant changes were observed in collections obtained from the control areas where there was no exposure to the insecticidal bait. A parallel study conducted within the Kansas site also documented that a significant shift in adult susceptibility occurred between managed and control areas during the first $3 \mathrm{yr}$ of the pilot program (Zhu et al. 2001). Differences in susceptibility of beetles collected from within and outside the managed areas suggest that rootworm populations respond rapidly to localized selection. Given that large differences in susceptibility to organophosphate insecticides among rootworm populations have been observed over relatively small geographic distances in Nebraska (Zhou et al. 2002), it seems that rootworm populations can respond to selection locally rather than over large geographic areas. It is clear that resistance genes do move among rootworm populations based on the documented spread of cyclodiene resistance in the early 1960s (Metcalf 1983) and more recently, the spread of methyl-parathion resistance among Nebraska populations (Zhou et al. 2002). However, at least during the initial stages of development, resistance seems to be more localized.

Significant differences in the responsiveness to the cucurbitacin-containing adjuvant Invite also were observed among collections from three managed areas relative to the control areas, suggesting that genes encoding both physiological and behavioral resistance factors were being co-selected in individuals from managed areas. Because baseline responsiveness data before initiation of the areawide management program is not available, the extent of natural variation in $D$. v. virgifera response to cucurbitacins within and among sites is unknown. Genetic variation in adult responsiveness to cucurbitacin B has been documented across widely separated geographic areas (Tallamy et al. 1997), but the relatively small distances separating managed and control areas within sites, and the consistency of the feeding bioassay results over three different environments suggest that selection for changes in behavioral response to cucurbitacin may be possible at small spatial scales. It should be noted that the cucurbitacin source used in behavioral assays [i.e., Invite, cucurbitacins derived from a bitter mutant of wild Hawkesbury watermelon, Citrullus lanatus (Thumb.)] was different from that used in aerial applications in the managed areas (i.e., SLAM, cucurbitacins derived from buffalo gourd, Cucurbita foetidissima H.B.K.) during most years of the program. Even though the profile of specific cucurbitacins that is present in each formulation differs, a large proportion of each profile is cucurbitacin E-glycoside (Metcalf and Metcalf 1992, Martin et al. 2002). We have not tested the level of resistance to the combination of insecticide and cucurbitacin, but it is possible that the combination of reduced susceptibility to carbaryl and reduced responsiveness to cucurbitacin could interact in an additive or synergistic way to dramatically reduce the efficacy of the insecticide/bait mixture.

It has previously been suggested that the strategy of combining contact insecticides with feeding stimulants might provide a multiple attack approach to prevent or at least delay resistance evolution (Siegfried et al. 1998). However, the results of the present investigations show decreases in both carbaryl susceptibility and cucurbitacin response among rootworm populations associated with the areawide management program. This clearly indicates that continued use of the insecticidal bait technology could eventually lead to control failures. These results suggest that if an areawide approach to rootworm management becomes widely practiced, alternative technologies (e.g., diversity of cucurbitacin attractants, alternative active ingredients, crop rotation, and transgenics) should be incorporated into the program. The use of multiple control tactics in a manner consistent with widely accepted resistance management theory and practice should serve to reduce selective pressures and sustain the areawide management concept.

\section{Acknowledgments}

Jim Brown helped collect and maintain D. v. virgifera field populations throughout the study. Kathryn Sterling provided assistance in preparation and running of electrophoresis studies. Numerous cooperators from each areawide management site provided adult rootworm collections throughout the study. Support for this project was provided by USDA Specific Cooperative Agreements 58-5447-6-116 and 585447-1-309. This is journal series paper 14560, Nebraska Agricultural Research Division, and contribution No. 1180 of the Department of Entomology, University of Nebraska.

\section{References Cited}

Ball, H. J., and G. T. Weekman. 1963. Differential resistance of corn rootworms to insecticides in Nebraska and adjoining states. J. Econ. Entomol. 56: 553-555. 
Bottrell, D., and D. R. Rummel. 1978. Response of Heliothis populations to insecticides applied in an area-wide reproduction diapause boll weevil suppression program. J. Econ. Entomol. 71: 87-92.

Comis, D. 1997. Corn Belt growers give areawide IPM a try. U.S. Dep. Agric.-ARS Agric. Res. 45: 4-7.

Finney, D. J. 1971. Probit analysis. Cambridge University Press, Cambridge, United Kingdom.

Hill, R. E., E. Hixson, and M. H. Mumma. 1948. Corn rootworm control tests with benzene hexachloride, DDT, nitrogen fertilizers, and crop rotations. J. Econ. Entomol. 41: 392-401.

Hollister, B., and C. A. Mullin. 1999. Isolation and identifications of primary metabolite feeding stimulants for adult western corn rootworm, Diabrotica virgifera virgifera LeConte, from host pollens. J. Chem. Ecol. 25: 12631280

Huber, R. T., L. Moore, and M. P. Hoffmann. 1979. Feasibility study of area-wide pheromone trapping of male pink bollworm Pectinophora gossypiella moths in a cotton insect pest management program. J. Econ. Entomol. 72: 222-227.

Knipling, E. F. 1980. Regional management of the fall armyworm, a realistic approach? Fla. Entomol. 63: 468 - 480.

Kunz, S. E., H. G. Kinzer, and J. A. Miller. 1983. Areawide cattle treatments on populations of horn flies (Diptera: Muscidae). J. Econ. Entomol. 76: 525-528.

LeOra Software. 1987. POLO-PC. A user's guide to probit and logit analysis. Berkeley, CA.

Levine, E., J. L. Spencer, S. A. Isard, D. W. Onstad, and M. E. Gray. 2002. Adaptation of the western corn rootworm to crop rotation: evolution of a new strain in response to a management practice. Am. Entomol. 48: 94-107.

Martin, P.A.W., M. Blackburn, R.F.W. Schroder, K. Matsuo, and B. W. Li. 2002. Stabilization of cucurbitacin E-glycoside, a feeding stimulant for diabroticite beetles, extracted from bitter hawksbury watermelon. J. Insect Sci. 2: $1-6$.

Mayo, Z. B. 1976. Aerial suppression of rootworm adults for larval control. Dept. Entomol. Rpt. No. 2, Univ. of Nebraska, Lincoln, NE.

Meinke, L. J. 1995. Adult corn rootworm management. Univ. Nebr. Agric. Res. Div. Misc. Publ. 63.

Meinke, L. J., B. D. Siegfried, R. J. Wright, and L. D. Chandler. 1998. Adult susceptibility of Nebraska western corn rootworm (Coleoptera: Chrysomelidae) populations to selected insecticides. J. Econ. Entomol. 91: 594600 .

Metcalf, R. L. 1983. Implications and prognosis of resistance to insecticides, pp. 703-733. In P.G.P. Georghiou and T. Sato (eds.), Pest resistance to pesticides. Plenum Press, New York.

Metcalf, R. L., and E. R. Metcalf. 1992. Plant kairomones in insect ecology and control. Chapman \& Hall, New York.

Miota, F., M. E. Scharf, M. Ono, P. Marçon, L. J. Meinke, R. J. Wright, L. D. Chandler, and B. D. Siegfried. 1998. Mechanisms of methyl- and ethyl-parathion resistance in the western corn rootworm. Pestic. Biochem. Physiol. 61: $39-52$.

O'Neal, M. E., C. D. DiFonzo, and D. A. Landis. 2002. Western corn rootworm (Coleoptera: Chrysomelidae) feed- ing on corn and soybean leaves affected by corn phenology. Environ. Entomol. 31: 285-292.

Parimi, S., L. J. Meinke, T. M. Nowatzki, L. D. Chandler, B. W. French, and B. D. Siegfried. 2003. Toxicity of insecticide-bait mixtures to insecticide resistant and susceptible western corn rootworms (Coleoptera: Chrysomelidae). Crop Protection 22: 781-786.

Pruess, K. P., J. F. Witkowski, and E. S. Raun. 1974. Population suppression of western corn rootworm by adult control with ULV malathion. J. Econ. Entomol. 67: 651655 .

Rabb, R. L. 1978. A sharp focus on insect populations and pest management from a wide area view. Bull. Entomol. Soc. Am. 24: 55-61.

Rummel, D. R. 1976. An area-wide boll weevil [Anthonomus grandis] suppression program. Organization, operation, and economic impact. Misc. Publ. Texas Agric. Exp. Stn. 1276: 152-159.

SAS Institute. 2001. SAS/STAT user's guide, SAS Institute, Cary, NC.

Scharf, M. E., L. J. Meinke, B. D. Siegfried, R. J. Wright, and L. D. Chandler. 1999a. Carbaryl susceptibility, diagnostic concentration determination, and synergism for U.S populations of western corn rootworm (Coleoptera: Chrysomelidae). J. Econ. Entomol. 92: 33-39.

Scharf, M. E., L. J. Meinke, R. J. Wright, L. D. Chandler, and B. D. Siegfried. 1999b. Metabolism of carbaryl by insecticide-resistant and -susceptible western corn rootworm populations (Coleoptera: Chrysomelidae). Pestic. Biochem. Physiol. 63: 85-96.

Siegfried, B. D., L. J. Meinke, and M. E. Scharf. 1998. Resistance management concerns for areawide management programs. J. Agric. Entomol. 15: 359-369.

Smith, R.F., and R. van den Bosch. 1967. Integrated control pp. 295-340. In W. W. Kilgore and R. L. Doutt [eds.], Pest Control: Biological, Physical, and Selected Chemical Methods. Academic Press, New York.

Tabashnik, B. E. 1992. Resistance risk assessment: realized heritability of resistance to Bacillus thuringiensis in diamondback moth (Lepidoptera: Plutellidae), tobacco budworm (Lepidoptera: Noctuidae), and Colorado Potato Beetle (Coleoptera: Chrysomelidae). J. Econ. Entomol. 85: 1551-1559.

Tallamy, D. W., P. M. Gorski, and J. D. Pesek. 1997. Intraand interspecific genetic variation in the gustatory perception of cucurbitacins by diabroticite rootworms (Coleoptera: Chrysomelidae). Environ. Entomol. 26: 13641372 .

Zhou, X., M. E. Scharf, S. Parimi, L. J. Meinke, R. J. Wright, L. D. Chandler, and B. D. Siegfried. 2002. Diagnostic assays based on esterase-mediated resistance mechanisms in western corn rootworms (Coleoptera: Chrysomelidae). J. Econ. Entomol. 95: 1261-1265.

Zhu, K. Y., G. E. Wilde, R. A. Higgins, P. E. Sloderbeck, L. L. Buschman, R. A. Shufran, R. J. Whitworth, S. R. Starkey, and F. He. 2001. Evidence of evolving carbaryl resistance in western corn rootworm (Coleoptera: Chrysomelidae) in Areawide-managed cornfields in north central Kansas. J. Econ. Entomol. 94: 929-934.

Received 12 April 2004; accepted 9 July 2004. 